\title{
1 Swelling effect on coal micro structure and associated
}

\section{2 permeability reduction}

3 Yihuai Zhang ${ }^{\mathrm{a}^{*}}$, Maxim Lebedev ${ }^{\mathrm{b}}$, Mohammad Sarmadivaleh ${ }^{\mathrm{a}}$, Ahmed Barifcani ${ }^{\mathrm{a}}$, Taufiq Rahman ${ }^{\mathrm{a}}$, and

4 Stefan Iglauer ${ }^{\mathrm{a}}$

$5 \quad$ a Department of Petroleum Engineering, Curtin University, 26 Dick Perry Avenue, 6151 Kensington, Australia

$6 \quad{ }^{b}$ Department of Exploration Geophysics, Curtin University, 26 Dick Perry Avenue, 6151 Kensington, Australia 7

$8 \quad$ *corresponding author (yihuai.zhang@postgrad.curtin.edu.au)

10 Abstract

11 Porosity and permeability of deep unmineable coal seams are key parameters in the context of (enhanced) coalbed methane recovery and $\mathrm{CO}_{2}$ geo-storage in coal beds as they determine productivity and injection rate. Porosity and permeability are again determined by the microstructure of the coal, and the cleat network-coal matrix system. Furthermore, it is well established that swelling of the coal matrix due to water adsorption can significantly reduce permeability. However, the exact effect of swelling due to water adsorption on the coal micro-structure is only poorly understood, and how this microstructural change impacts on the permeability and porosity characteristics of the coal. We thus imaged dry coal plugs and swollen coal plugs (swollen due to brine adsorption) at high resolution $(3.43 \mu \mathrm{m})^{3}$ in $3 \mathrm{D}$ with an X-ray micro-computed tomograph (microCT). On the microCT images two types of cleats were identified; cleats in the coal matrix and cleats syngeneic with the mineral phase. Approximately $80 \%$ of the coal matrix cleats closed upon water adsorption, while the cleats in the mineral phase were not affected. This cleat closure by water adsorption dramatically 
reduced porosity and particularly permeability, consistent with dynamic permeability core-

Keywords: coal; swelling; cleat; microCT; porosity; permeability.

\section{Introduction}

Coalbed methane recovery $(\mathrm{CBM})$ has gained substantial interest in recent years. Essentially $\mathrm{CBM}$ is a method to produce natural gas from deep unmineable coal seams, and it utilizes pressure-driven fluid flow for hydrocarbon recovery, often in combination with hydraulic fracturing [1] or $\mathrm{N}_{2} / \mathrm{CO}_{2}$ injection for enhanced production (ECBM) [2, 3]. However, the coal permeability is dramatically reduced by several orders of magnitude $[4,5]$ due to water $[6,7]$ or gas $[8,5]$ adsorption, which cause coal swelling and seriously limits the application of this technology [8]. Water adsorption, on which we focus here, has also been suggested to decrease the sorption capacity of $\mathrm{CO}_{2} / \mathrm{CH}_{4} / \mathrm{N}_{2}$ in $\mathrm{CBM} / \mathrm{ECBM}$ and storage volume for $\mathrm{CO}_{2}$ geo-sequestration $[9,10]$. Water encroachment and associated water adsorption, however, is natural during $\mathrm{CBM} / \mathrm{ECBM}$ and $\mathrm{CO}_{2}$ storage in coal seams [11].

To address these issues and to predict CBM production, several coal swelling - permeability models were built, and the swelling characteristics are typically simulated by coal matrix strain change (e.g. [12], [13]). However, these models failed to explain stress controlled swelling laboratory test results [14] and thus newer strain model [15] have been tuned to match the laboratory results. These models, however, still have significant limitations with respect to predicting the effect of water swelling on porosity and permeability. Specifically, these models treat the swelling effect as independent of the fracture system, i.e. the cleats are 
fixed or only change due to effective stress changes; while it has been suggested that swelling may close the cleats and thus reduce permeability $[16,17,18]$.

Thus to fully understand the cleat system is of vital importance. Note that typically macro cleats and micro cleats $(<20 \mu \mathrm{m})$, on which we focus here, are distinguished. Such micro cleats have been analysed with medical x-ray computed tomography (medicalCT) (e.g. [19, 20]) and SEM (e.g. [21-24]). However, medicalCT has a relatively low resolution $(\sim 500 \mu \mathrm{m})^{3}$ [25] and the coal microstructure (i.e. micro cleat system) cannot be resolved; while SEM only produces $2 \mathrm{D}$ information of the sample surface, and that usually at vacuum conditions. The detailed 3D morphological characteristics are, however, vital as 2D space has significantly different fluid mechanical properties (e.g. the percolation threshold is much lower in 3D than in 2D, [26] ). More recently, x-ray micro-computed tomography (microCT) - which has a significantly higher resolution than medicalCT - has been increasingly used in petrophysical studies (e.g. compare the reviews by [27], [28] or [29] or for example [30], [31]), and the micro structure of coal was imaged (e.g. [24], [32], [33]). However, there is a serious lack of information regarding the effects of water swelling on the microstructure. We thus now expanded on this microCT analysis and investigated how water swelling influences the 3D morphology of coal at the micro-meter level.

\section{Experimental Methodology}

\subsection{Materials}

A coal block was acquired from a depth of $750 \mathrm{~m}$ in the Pingdingshan Ten coal mine, Henan Province of China. The coal was a typical sub-bituminous coal (medium rank) with carbon content $54( \pm 2) \%$ and volatile matter content $36( \pm 1) \%$, measured by Chinese Standards GB/T 212-2008 and DL/T 1030-2006. Stripes of white minerals were identified visually with 
73 sporadic distribution on the coal sample surface. Small samples were cut from adjacent 74 positions from the block, and subjected to SEM and EDS analysis, Fig. 1. The coal had a 75 relatively high oxygen content ( $\sim 30 \mathrm{wt} \%$; cp. points A and D in Fig. 1); the minerals were 76 identified as $\mathrm{CaCO}_{3}$ (cp. points $\mathrm{B}$ and $\mathrm{C}$ in Fig. 1). Furthermore, a small dry coal plug (5mm 77 diameter, $10 \mathrm{~mm}$ length) was cut, again from the same block and a position adjacent to the 78 other samples, and this plug (Sample A) was imaged with an x-ray micro-computed 79 tomography (Xradia Versa-XRM) at a high resolution of $(3.43 \mu \mathrm{m})^{3}$. X-ray accelerating 80 voltage was chosen as $40 \mathrm{kV}$, the $\mathrm{x}$-ray beam size was approximately $0.3 \mu \mathrm{m}$, and a $1000 \mathrm{x}$ 811000 pixel detector was used for radiograph acquisition Total time for 3D imaging of the 82 sample was $\sim 4$ hours. 

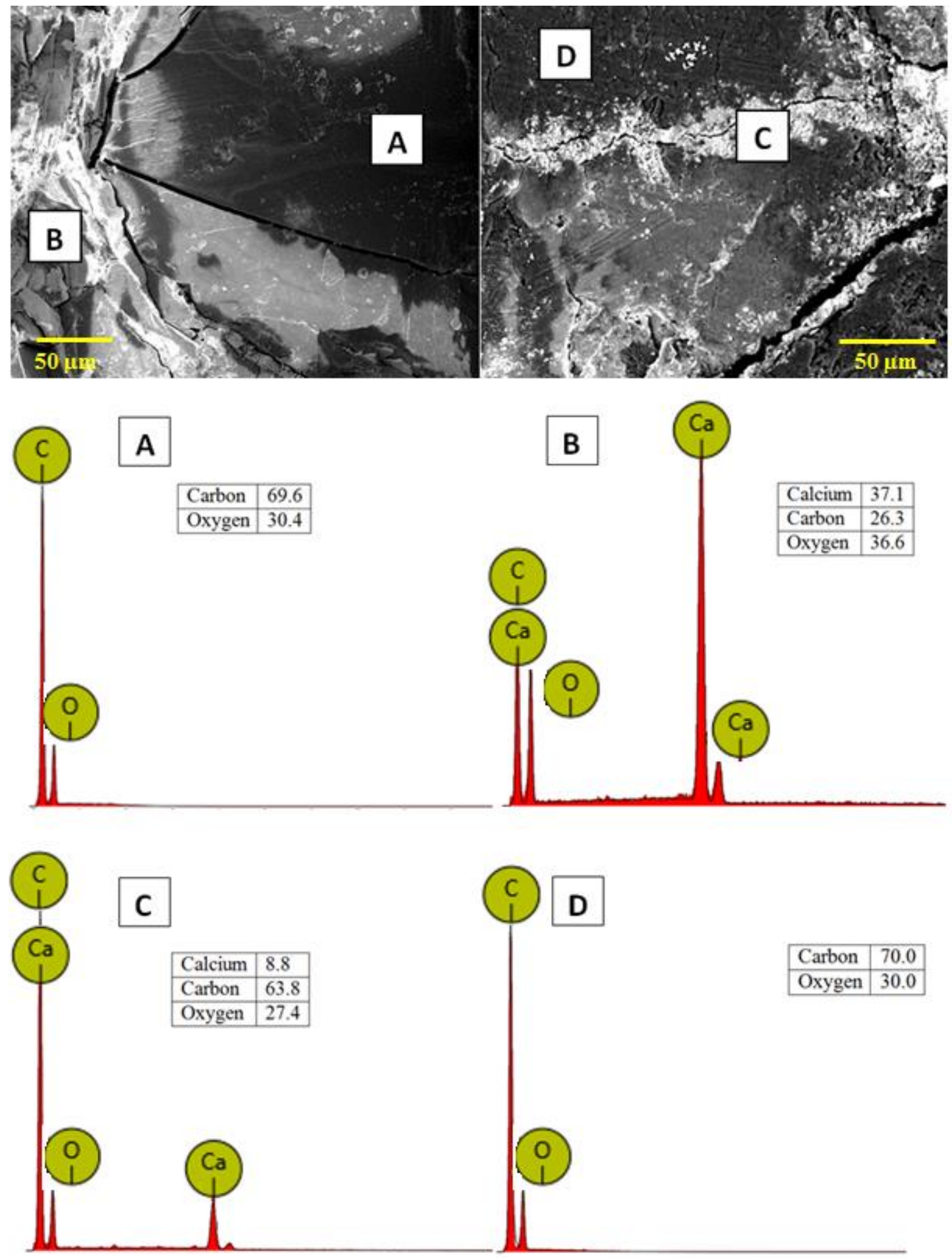

83

84 Fig. 1. SEM images of the coal sample with elemental compositions (wt \% measured by 85 EDS) for different points A, B, C and D indicated. 
88

89

90

91

92

93

94

95

96

97

98

99

100

101

102

An experimental core flood apparatus was built for gas and brine permeability measurements

(Fig. 2). The small coal plug was mounted into an X-ray transparent flow cell, and the whole apparatus was vacuumed for 12 hours to ensure that there is no air inside the plug sample or the tube system. A confining pressure of $5 \mathrm{MPa}$ was applied, and subsequently more than 7000 pore volumes (PV) of brine $(5 \mathrm{wt} \% \mathrm{NaCl}$ in deionized water) were injected at a flow rate of $0.02 \mathrm{~mL} / \mathrm{min}$ through the plug with a high precision syringe pump (Teledyne ISCO 500D) at $296 \mathrm{~K}$; and the pressure drop across the plug was continuously measured with high accuracy pressure sensors (Keller PAA-33X, accuracy 0.1\%). Permeability was then calculated using Darcy's law. This test was repeated thrice to test repeatability; all the three samples (Sample A, Sample B and Sample C) were cut from the same coal block.

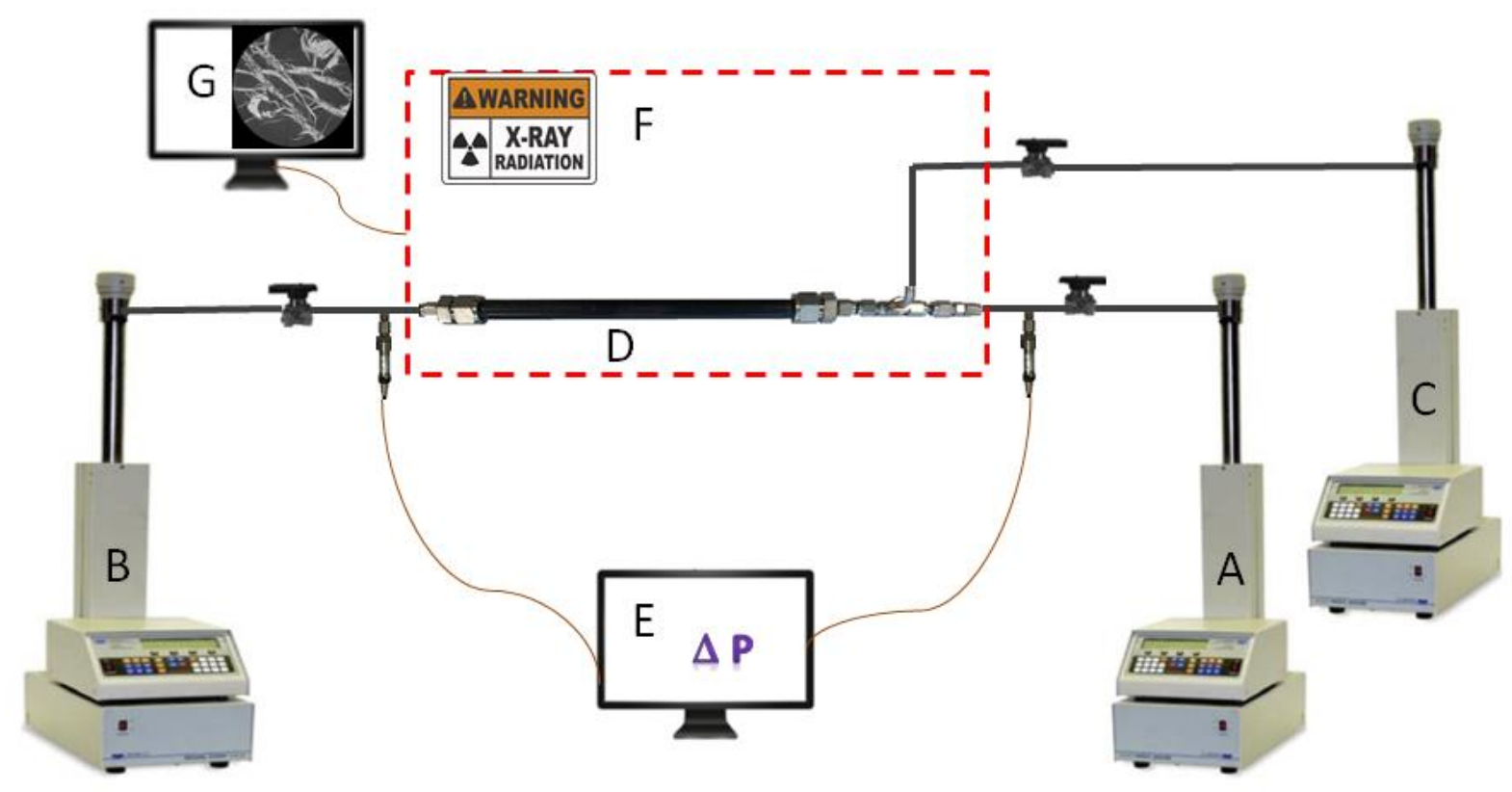

Fig. 2. Experimental apparatus used; (A) injection pump, (B) production pump, (C) confining pressure pump, (D) core holder, (E) pressure data acquisition, (F) microCT, (G) microCT images processing. 
103

104

Injection was stopped after $\sim 120$ hours flooding time (when the permeability reduced by > $80 \%$, Fig. 11), and the brine saturated plug was microCT imaged again at the same high resolution (without confining stress). . Note that the plug was mechanically fixed inside the microCT cell; thus the same sample volume was imaged. All microCT images were filtered with a non-local means filter [34] and segmented with a watershed algorithm [35] [36] Fig. 3.
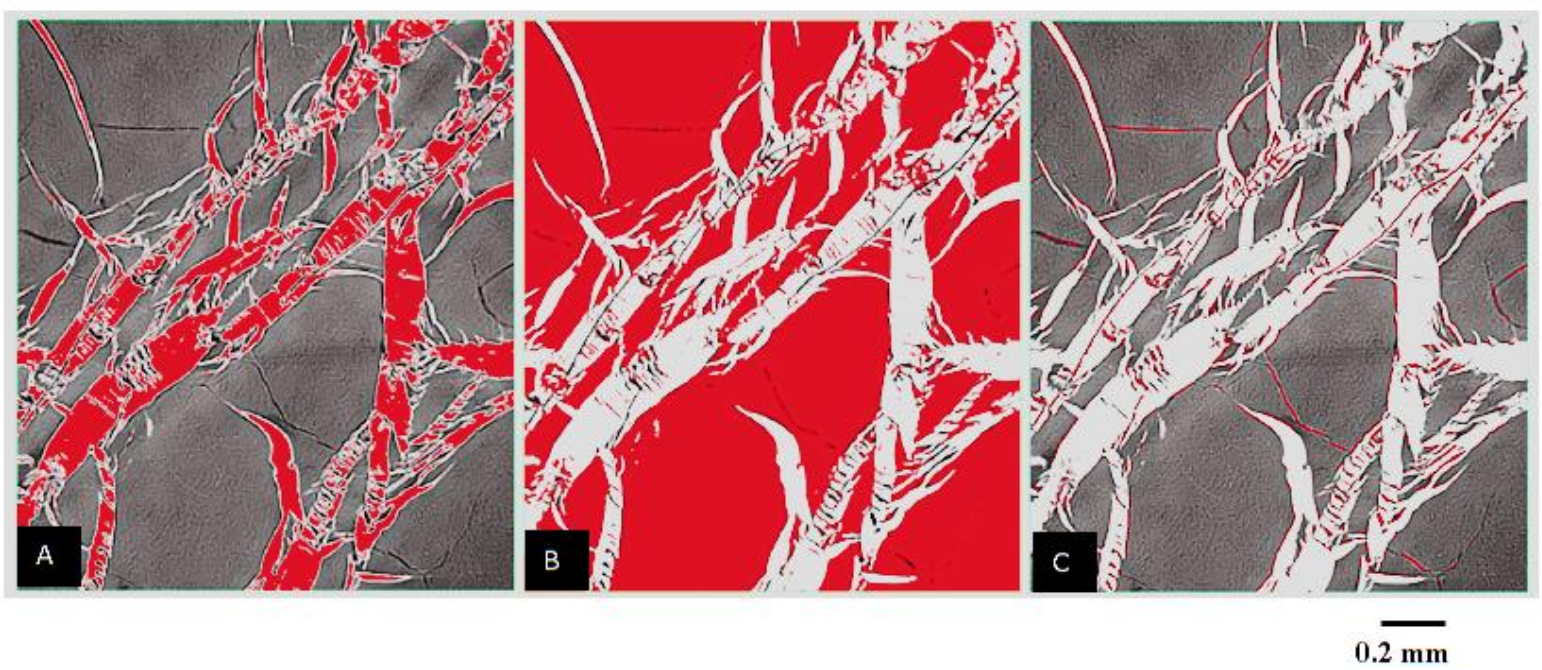

Fig. 3. Axial slices through the segmented microCT coal sample image: (A) calcium carbonate minerals (red), (B) coal matrix (red), (C) micro cleats (red).

\section{Results and Discussion}

\subsection{Microstructure characteristics and segmented phases}

Three phases were clearly identified in the raw and segmented 2D/3D microCT images: micro cleats (black), coal matrix (grey) and minerals (white) in raw images (Fig. 4a); with white, blue and red in the segmented images (Fig. 4b). The widths of the micro cleats in the dry plug were 5-10 $\mu \mathrm{m}$ (no confining stress), while lengths up to $2 \mathrm{~mm}$ were measured. These micro-cleats can be divided into two groups according to their location in the sample: they 

in Fig. 4a or C in Fig. 1). Clearly, the coal sample's microstructure is highly heterogeneous.

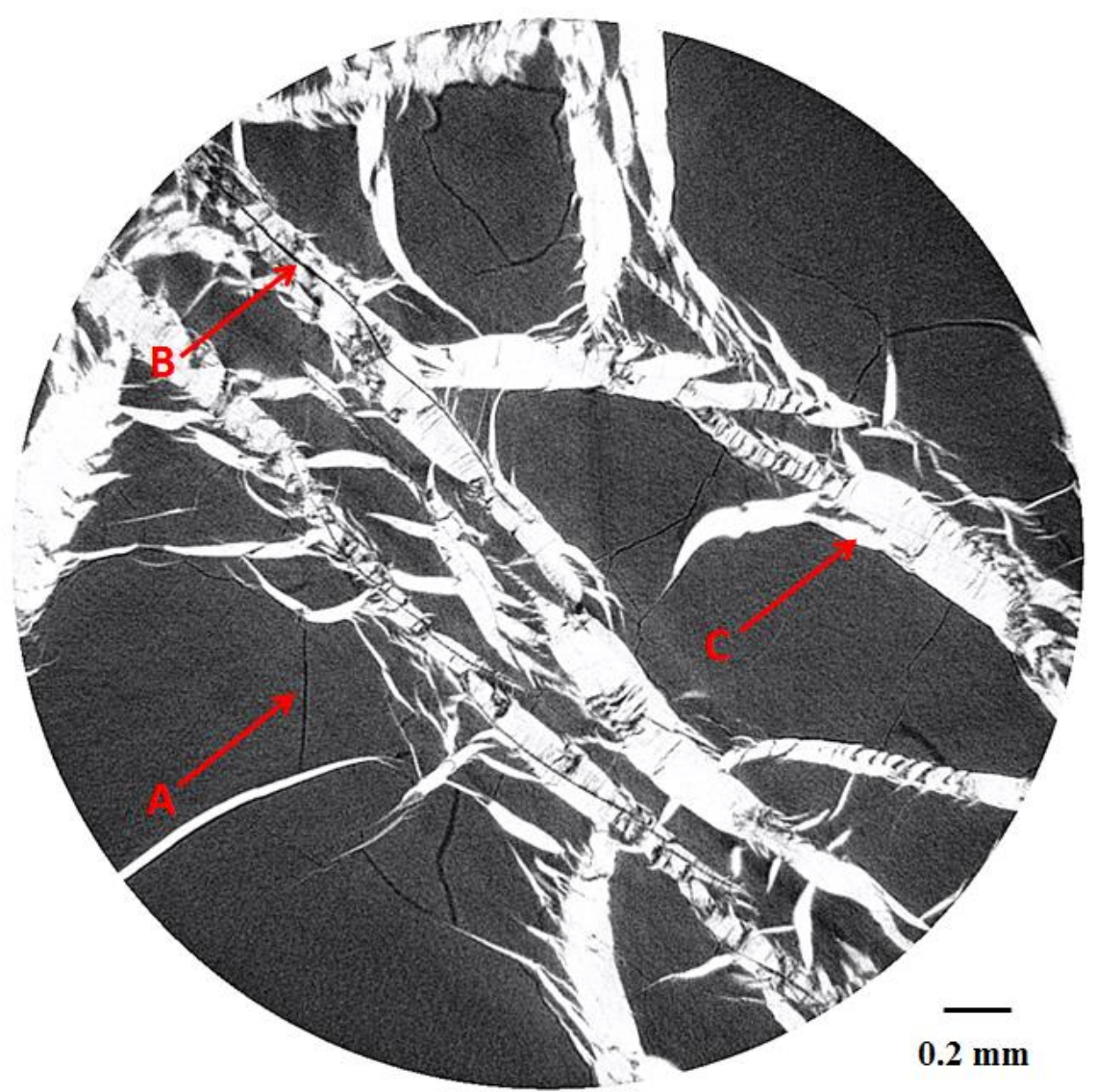

122 Fig. 4a. Axial 2D slice through the dry coal (3.43 $\mu \mathrm{m}$ resolution; raw image); the different

123 features can be clearly identified: (A) micro cleat in the coal matrix, (B) cleat inside mineral, 124 (C) mineral phase. 


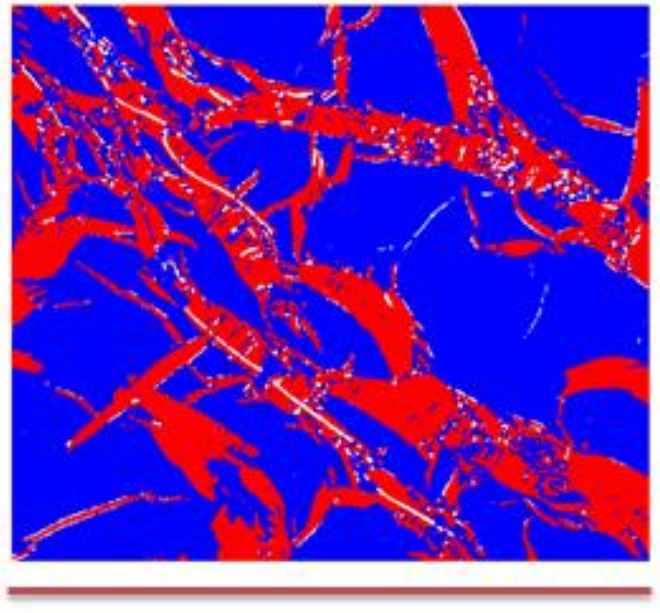

$2.34 \mathrm{~mm}$

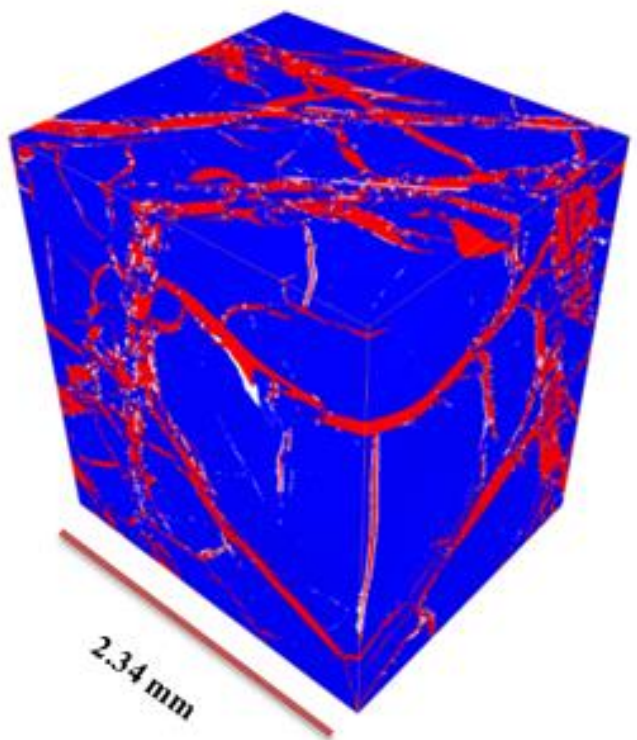

Fig. 4b. 2D and 3D views of the segmented coal sample; three phases were identified: micro cleats (white); mineral phase (red); and coal matrix (blue).

\subsection{Microstructure evolution due to swelling}

\subsubsection{Qualitative analysis}

A clear change in the micro-structure was observed on the microCT images before and after swelling (Fig. 5). Essentially the cleats in the coal matrix disappeared after the sample was saturated with brine. However, no significant change was observed in terms of the mineral phase and the cleats inside the mineral phase. In this context the concept of "internal swelling stress" was proposed [37]; essentially, the coal "internal swelling stress" closed the cleats; at the same time, the mineral phase had no such "internal swelling stress" and it is less compressible, thus the open cleats were protected from closure by the mineral phase. The micro cleats and generally the pore volume decreased significantly when the sample was saturated, this is clearer in the segmented images (Fig. 6). All these evidence indicated that water absorption into the coal matrix and associated coal matrix swelling. 


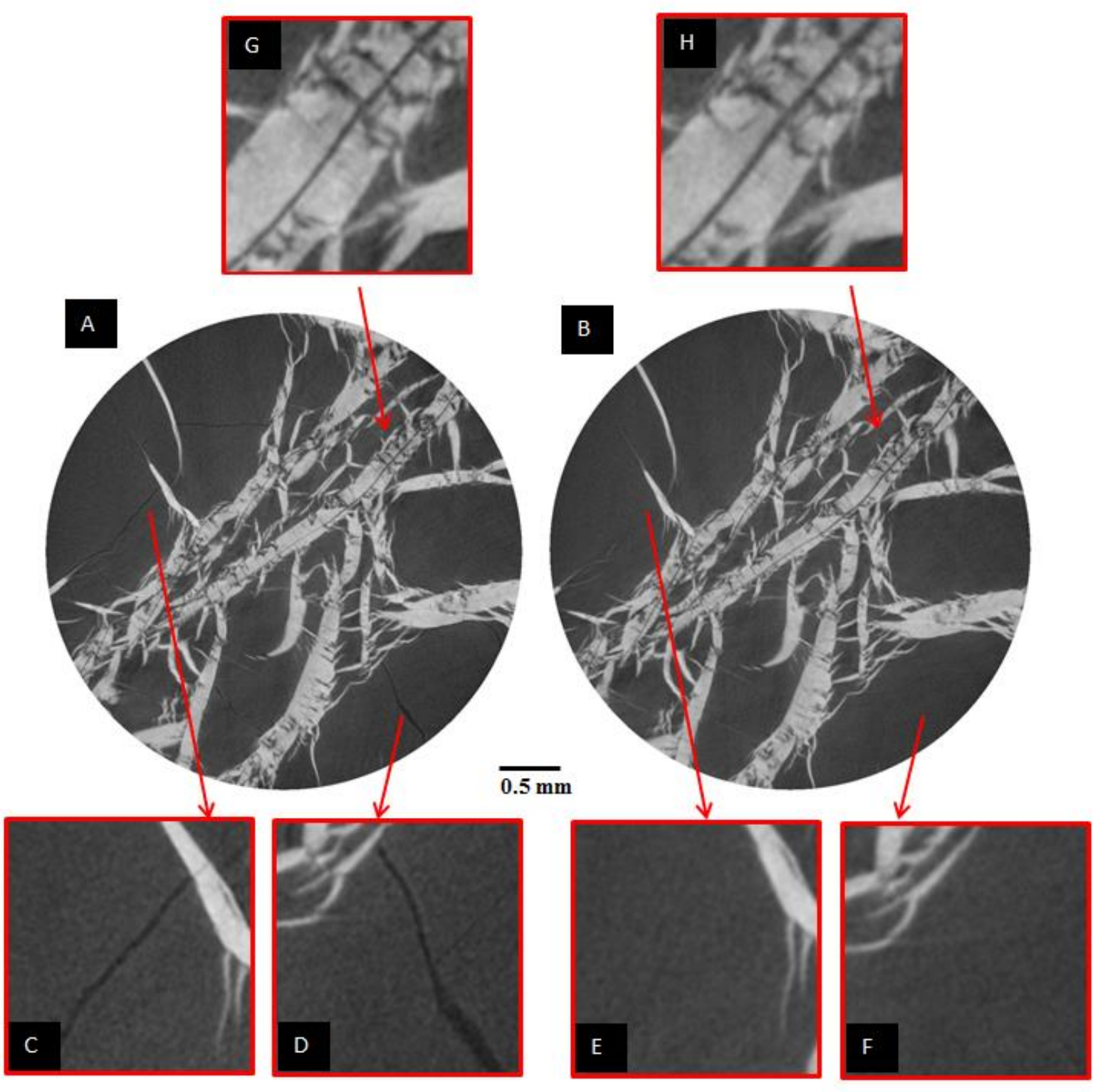

143 Fig. 5. Axial 2D image slices through the coal plug (raw image); (A) dry sample, (B) brine 144 saturated sample (same slice), (C and D) zoomed-into image A: the cleats and minerals can 145 be seen clearly, (E and F) the sample area as shown in C and D: the cleats disappeared but the 146 mineral phase did not change, $(\mathrm{G}$ and $\mathrm{H})$ the cleats inside minerals showed no change before 147 and after brine saturation. 

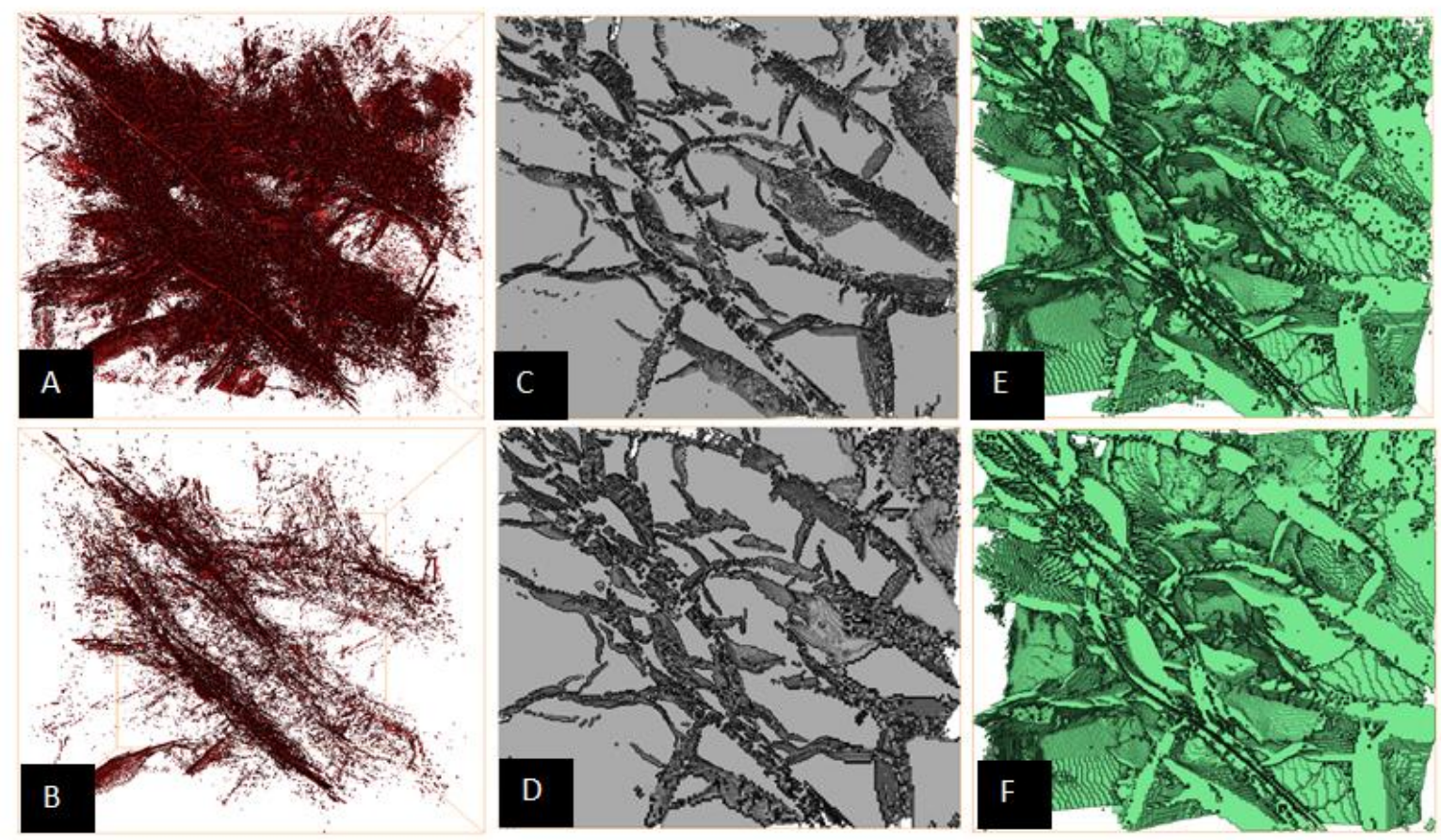

$0.2 \mathrm{~mm}$

Fig. 6. 3D images of the three segmented phases; (A) micro cleats, dry plug; (B) micro cleats, brine saturated plug; (C) coal matrix (shown in grey), dry plug; (D) coal matrix, brine saturated plug; (E) mineral phase, dry plug; (F) mineral phase, saturated plug.

\subsubsection{Quantitative analysis}

The microCT images were further analysed and the volume fractions of the different phases were measured before and after brine saturation. The micro cleat volume shrank significantly (by $\sim 75 \%$ ) due to brine saturation, while the coal matrix volume increased by the same nominal amount, but the mineral fraction volume stayed approximately constant, Table 1.

Table 1

Volume fractions of the different phases in the coal plug measured on the micro-CT images. 


\begin{tabular}{lll}
\hline & Dry plug & Saturated plug \\
\hline Micro cleats total $(\%)$ & $2.85 \%$ & $0.71 \%$ \\
Micro cleats - & $1.20 \%$ & $0.19 \%$ \\
Below threshold size $(\%)^{*}$ & & \\
Micro cleats - & $1.65 \%$ & $0.52 \%$ \\
Above threshold size $(\%)^{*}$ & & \\
Minerals $(\%)$ & $28.79 \%$ & $28.83 \%$ \\
Coal matrix $(\%)$ & $68.36 \%$ & $70.46 \%$ \\
Effective cleat porosity & $1.19 \%$ & $0.19 \%$ \\
\hline
\end{tabular}

*Cross-sectional threshold value $=50000 \mu \mathrm{m}^{2}$.

The 3D topographies (A and B in Fig. 7) illustrate how the micro cleats changed due to brine saturation. The cross sectional area $\left(\mu \mathrm{m}^{2}\right)$ was chose as the threshold value which is better description for the morphology of cleats (thin and long) than the volume $\left(\mu \mathrm{m}^{3}\right)$ value, We further divided small micro cleats ( $\mathrm{C}$ and $\mathrm{D}$ in Fig. 7; all void cross-sectional areas $\leq 50000$ $\mu \mathrm{m}^{2}$ ) and larger micro cleats (E and $\mathrm{F}$ in Fig. 7) for better visualization; all void space significantly shrank due to brine saturation, furthermore almost all larger micro cleats were oriented vertically where along the coal bed. The absolute porosity $(\phi)$ for each image slice was computed, and $\phi$ was clearly reduced by swelling throughout the plug (Fig. 8). We further analysed the effective porosity $\left(\phi_{\mathrm{e}}\right) ; \phi_{\mathrm{e}}$ also dramatically decreased (from $1.19 \%$ to $0.19 \%)$.This is consistent with our pore size distribution measurements on the microCT 174 images: all micro-cleats shrank, particularly the larger ones (Fig. 9). Finally we extracted a 175 pore network for the dry and brine saturated plug with a skeletonization algorithm [38], Figure 10; clearly the number of fluid conduits was significantly reduced by brine saturation. 


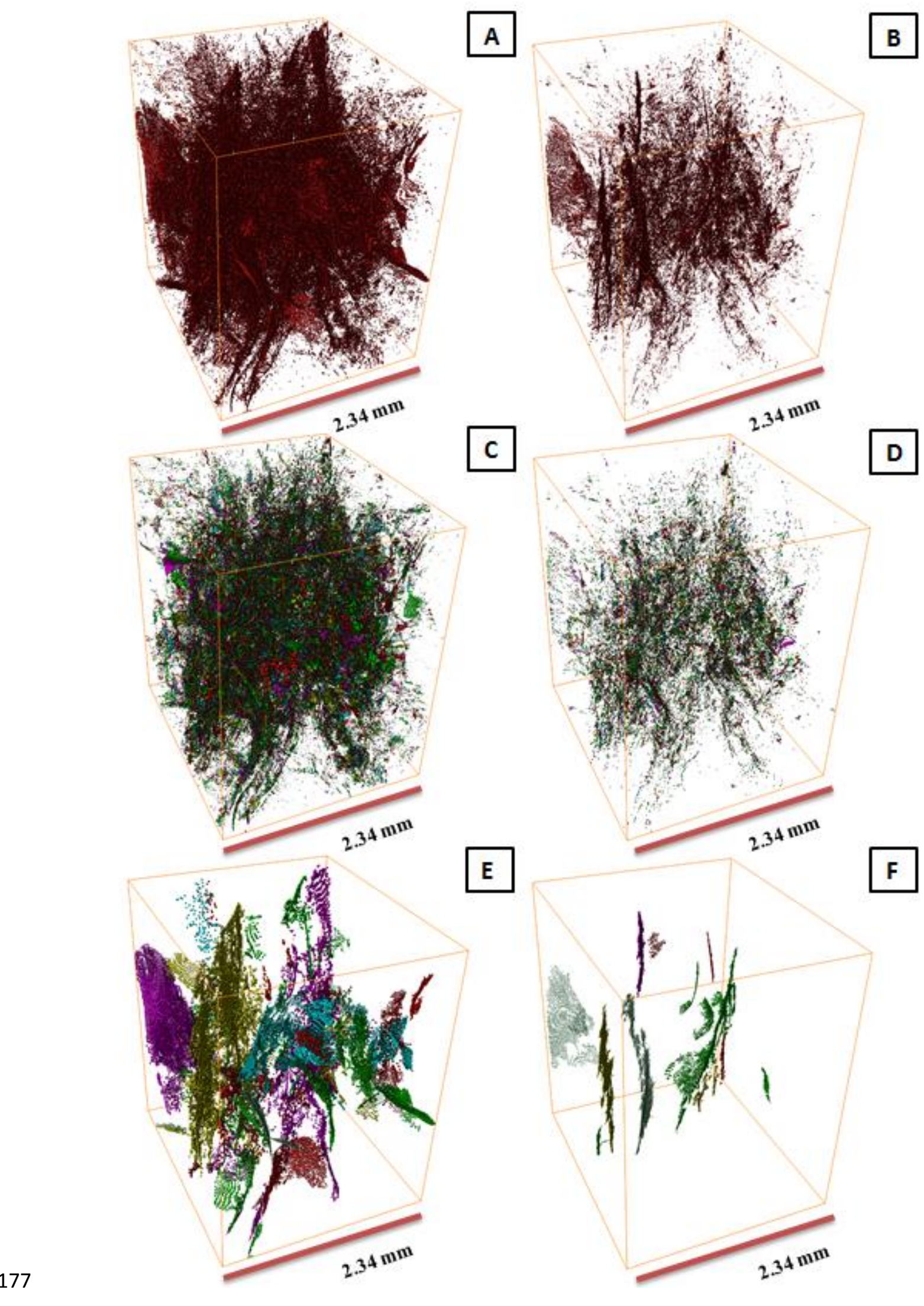

178 Fig. 7. 3D visualization of the micro cleat system before (left) and after (right) brine 179 saturation; a threshold value of $50000 \mu \mathrm{m}^{2}$ was set for the cleat cross-sectional area to 
180 distinguish smaller and larger cleats; (A) micro cleats, dry sample; (B) micro cleats, brine 181 saturated plug; (C) micro cleats $\left(\leq 50000 \mu \mathrm{m}^{2}\right)$, dry sample; (D) micro cleats $\left(\leq 50000 \mu \mathrm{m}^{2}\right)$, 182 saturated plug; (E) micro cleats $\left(>50000 \mu \mathrm{m}^{2}\right)$, dry sample; (F) micro cleats $\left(>50000 \mu \mathrm{m}^{2}\right)$, 183 saturated plug.

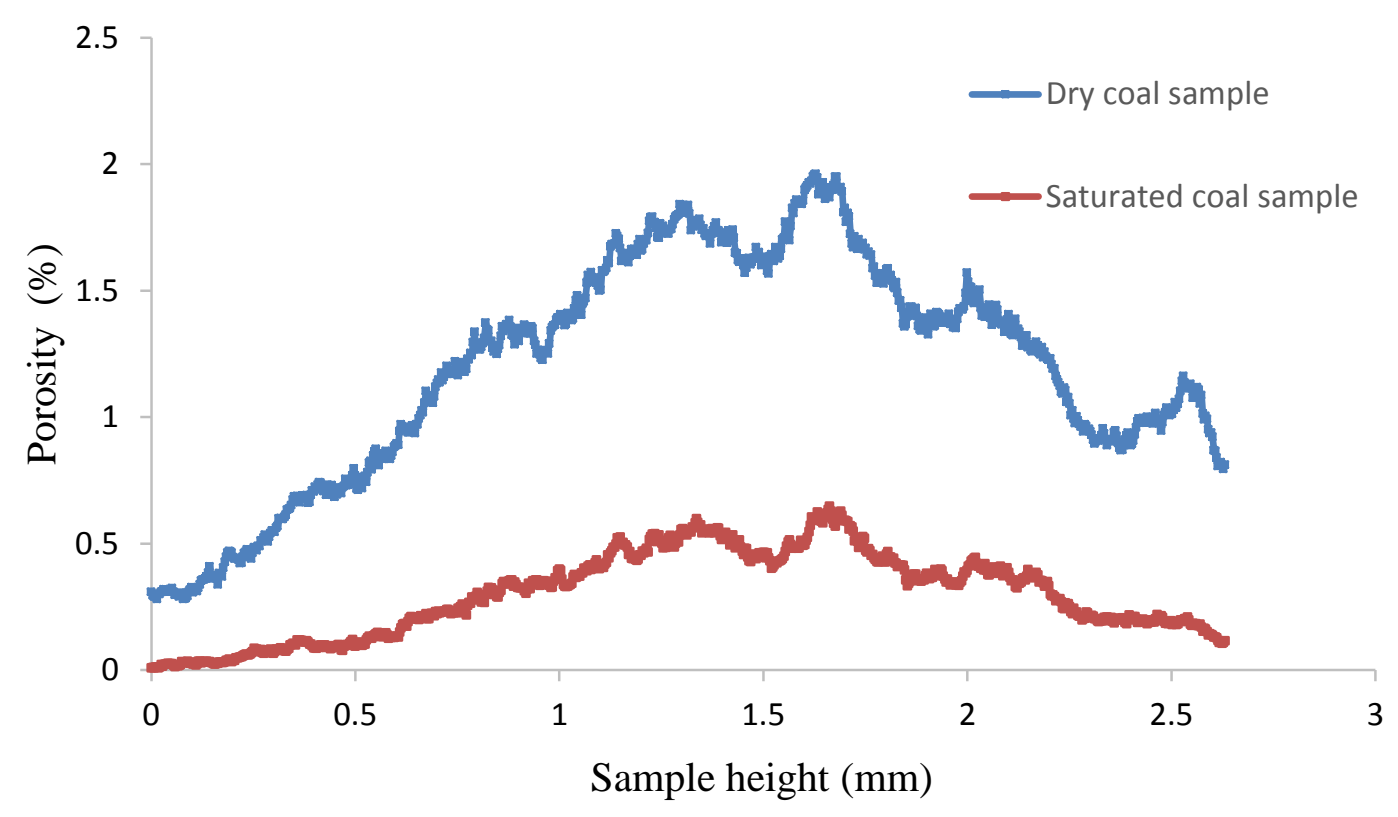

Fig. 8. Porosity versus sample height. 


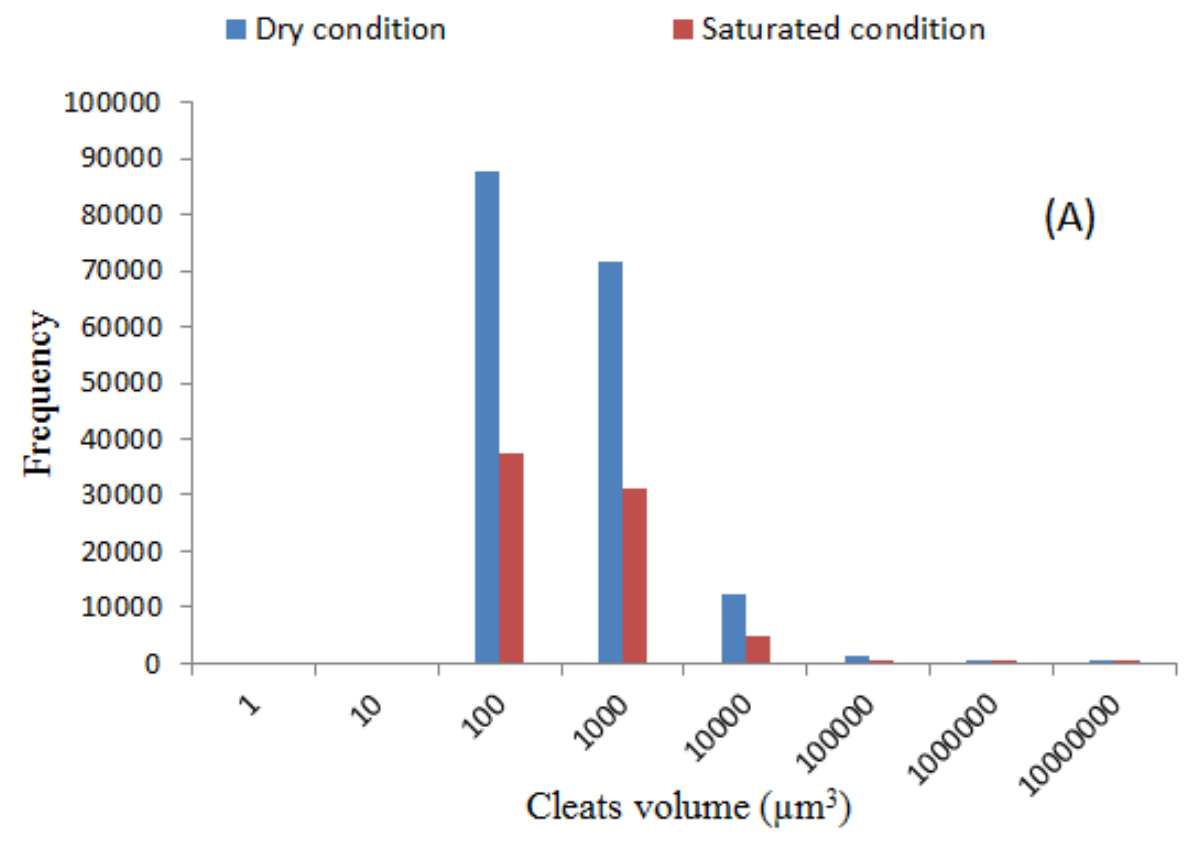

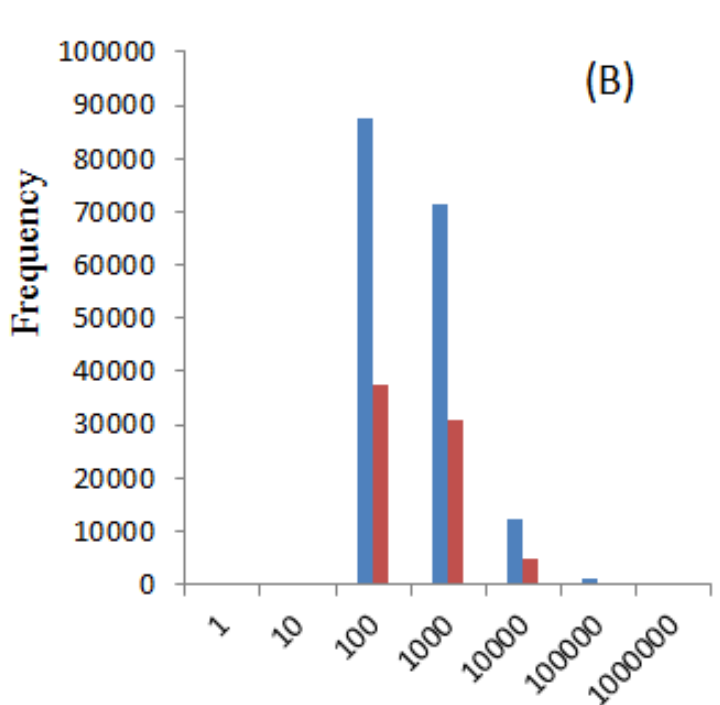

Cleats volume $\left(\mu \mathrm{m}^{3}\right)$

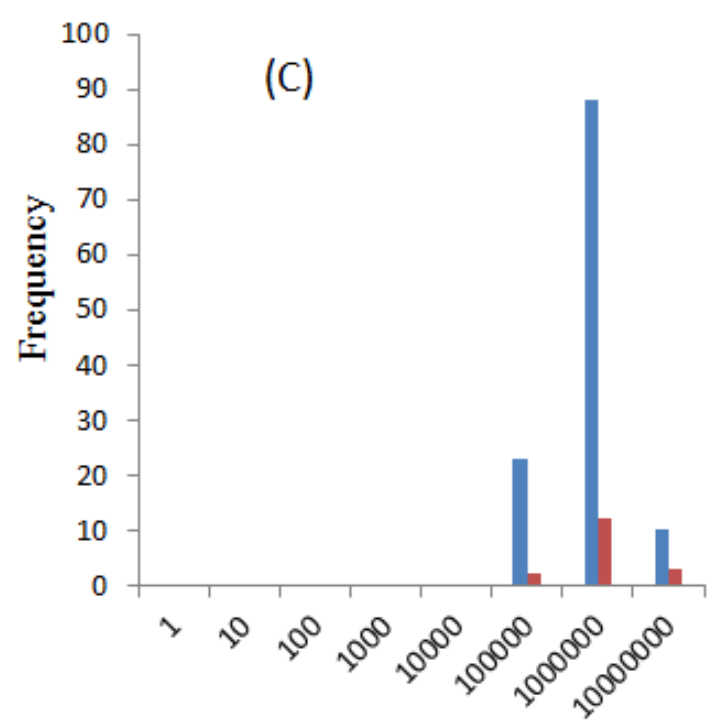

Cleat volume $\left(\mu \mathrm{m}^{3}\right)$

189 Fig. 9. Cleat size distributions before and after swelling (caused by brine saturation); (a) all 190 cleats; (b) cleats $\leq 50000 \mu \mathrm{m}^{2}$; (c) cleats $>50000 \mu \mathrm{m}^{2} .50000 \mu \mathrm{m}^{2}$ is the threshold value of 191 cross-sectional void area. 

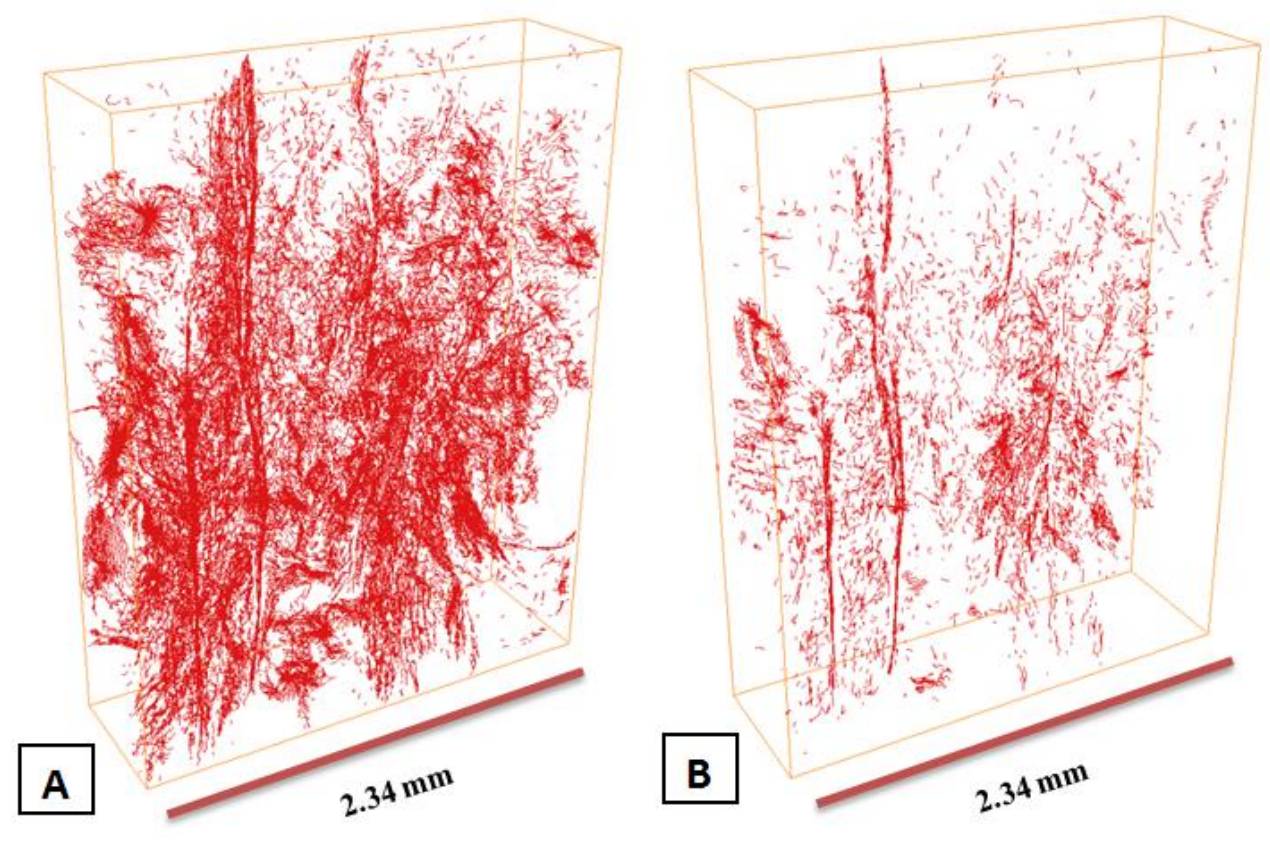

194 Fig. 10. Pore networks extracted by skeletonization algorithm [38], no confining stress; (A) 195 dry coal sample; (B) brine saturated coal sample.

\subsection{Permeability evolution}

The dynamic permeability during brine injection was measured on three separate plugs

199 (Sample A, B and C), see above in the methodology section. Permeability consistently dropped rapidly in the first 60 hours of the experiment ( 3700 PV of brine injected), Figure

11. This permeability drop can be fitted with logarithmic curves (printed onto the graphs in Fig. 11). However, the plugs had significantly different absolute permeabilities; which is expected as coal is a rather heterogeneous material (cp. section 3.1). The graphs were quite similar though, all samples underwent a $>80 \%$ permeability loss after injection of $\sim 7300 \mathrm{PV}$ of brine. This permeability drop is consistent with the microCT analysis above: porosity significantly reduced during the water absorption process (from $2.85 \%$ to $0.81 \%$ ); and 

induced by coal matrix swelling.

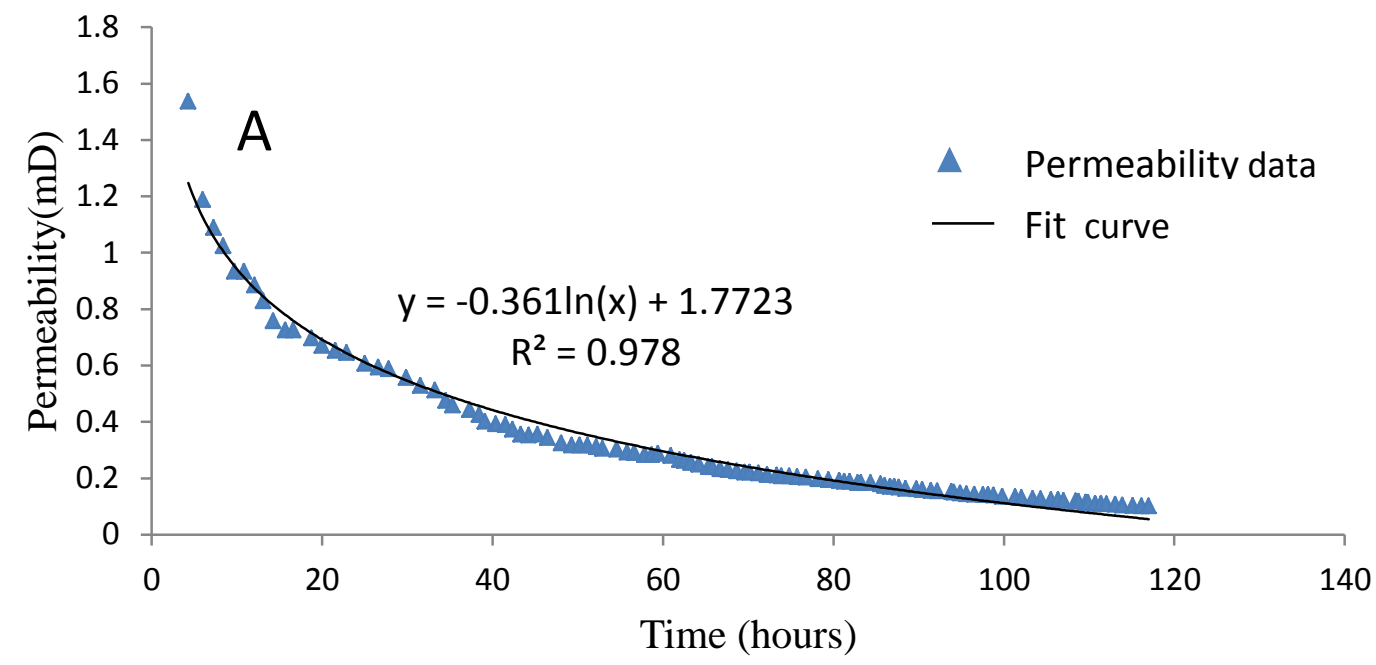

209

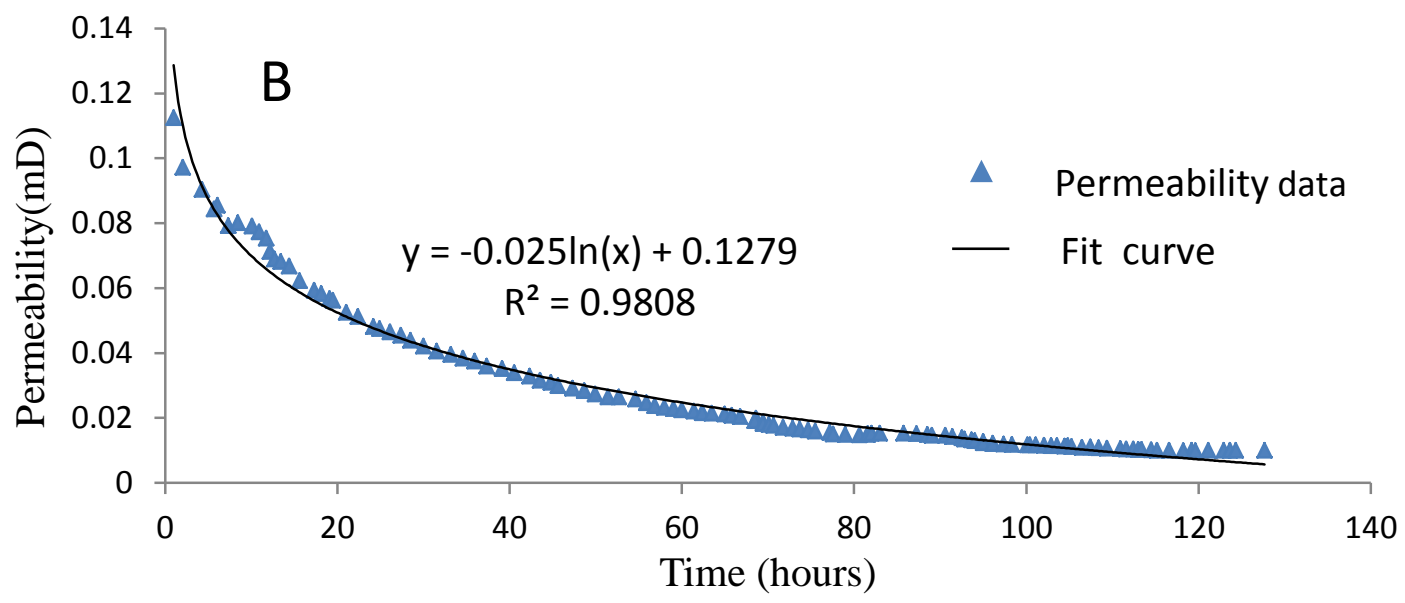

210

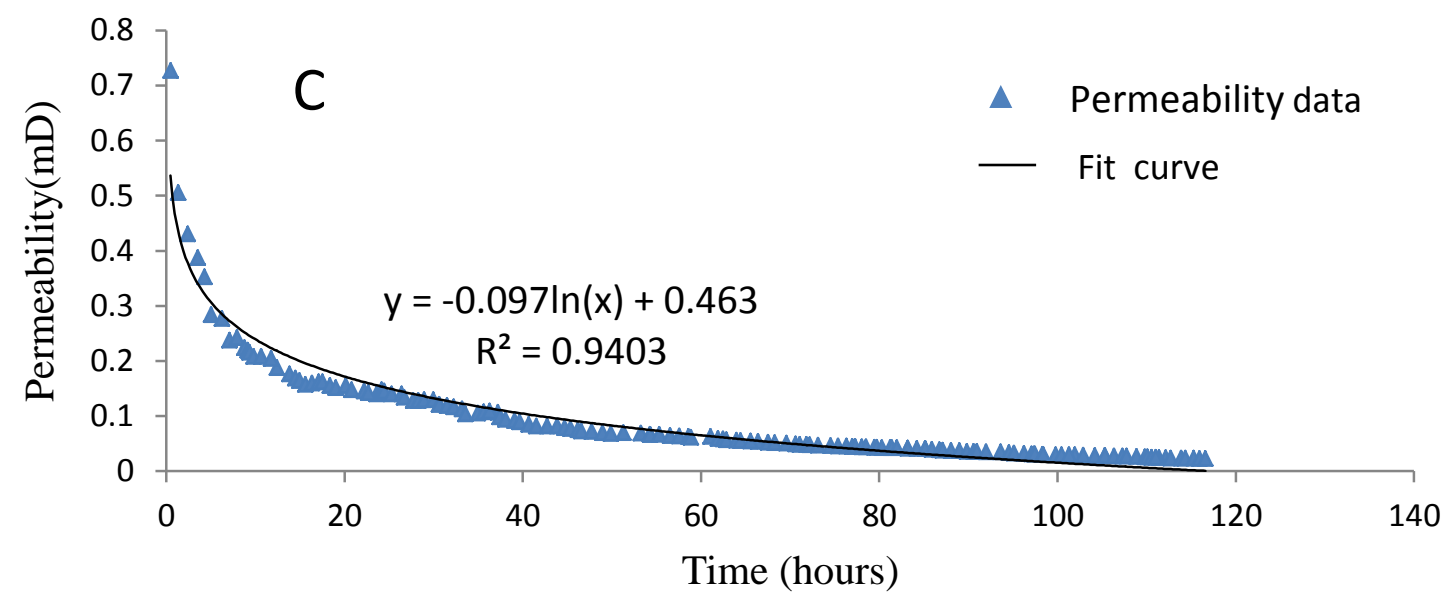


213 Fig. 11. Dynamic permeability versus brine injection time for the three coal samples tested

214 (confining stress $=5 \mathrm{MPa}$ ), brine was injected at a flow rate of $0.02 \mathrm{~mL} / \mathrm{min}$ (i.e. $100 \mathrm{~h}$ 215 correspond to $\sim 6200 \mathrm{PV}$ of brine injected); A for sample A, B for sample B and C for sample 216 C.

\section{Conclusions}

219

Coal porosity and permeability are key parameters as they control natural gas production from deep (unmineable) coal seams $[39,40,41]$. However, the microstructure of the coal which ultimately determines coal porosity and permeability - is only poorly understood. This is especially true for the effect of swelling on the microstructure (e.g. [42]) - which is a wellknown cause for permeability change (e.g. [17])

Thus we imaged dry and swollen (due to brine absorption) coal plugs with $3 \mathrm{D}$ microCT at a high voxel resolution $(3.4 \mu \mathrm{m})^{3}$. The dry images were similar to those acquired by [33] and [24]; and the medium rank coal was highly heterogeneous and had a low porosity $(2.85 \% \pm$ $1 \%)$ and permeability $(\sim 0.1 \mathrm{mD}-10 \mathrm{mD})$ and a significant mineral content. Micro cleats were visible in the coal matrix and the mineral phase, consistent with SEM imaging (cp. Fig. 1). However, when brine was injected into a dry coal plug, more than $80 \%$ of these cleats closed due to swelling, which caused a dramatic reduction in porosity and particularly permeability. But the cleats in the mineral phase were still open after the coal matrix swelling; this could be explained by the lower internal stress in the mineral and the lower compressibility of the mineral. 

permeability.

\section{Acknowledgment}

The authors thank the National Geosequestration Laboratory (NGL) of Australia for providing access to the X-ray microscope VersaXRM-500 (Zeiss-Xradia) . Funding for this facility was provided by the Australian Federal Government.

\section{References}

[1] S. Holditch, J. Ely, M. Semmelbeck, R. Carter, J. Hinkel, R. Jeffrey Jr, Enhanced recovery of coalbed methane through hydraulic fracturing, in: SPE Annual Technical Conference and Exhibition, Society of Petroleum Engineers, 1988.

[2] S.R. Reeves, Geological Sequestration of $\mathrm{CO} 2$ in Deep, Unmineable Coalbeds: An Integrated Research and Commerical-Scale Field Demonstration Project, in: SPE annual technical conference and exhibition, Society of Petroleum Engineers, 2001. [3] S. Reeves, D. Davis, A. Oudinot, A technical and economic sensitivity study of enhanced coalbed methane recovery and carbon sequestration in coal, DOE topical report, (2004). [4] L. Pekot, S. Reeves, Modeling the effects of matrix shrinkage and differential swelling on coalbed methane recovery and carbon sequestration, in: Paper 0328, proc. 2003 International Coalbed Methane Symposium. University of Alabama, Citeseer, 2003.

257 [5] J. Shi, S. Durucan, CO2 storage in deep unminable coal seams, Oil \& gas science and technology, $25860(2005)$ 547-558.

259 [6] P.L. Walker, S.K. Verma, J. Rivera-Utrilla, A. Davis, Densities, porosities and surface areas of coal macerals as measured by their interaction with gases, vapours and liquids, Fuel, 67 (1988) 1615-

2611623.

262 [7] D. Charrière, P. Behra, Water sorption on coals, Journal of colloid and interface science, 344 263 (2010) 460-467.

264 [8] S.R. Reeves, The Coal-Seq project: Key results from field, laboratory and modeling studies, in: Proceedings of the 7th International Conference on Greenhouse Gas Control Technologies (GHGT-7), 266 Citeseer, 2004, pp. 1399-1406.

267 [9] B. Krooss, F. Van Bergen, Y. Gensterblum, N. Siemons, H. Pagnier, P. David, High-pressure methane and carbon dioxide adsorption on dry and moisture-equilibrated Pennsylvanian coals, International Journal of Coal Geology, 51 (2002) 69-92. 
[11] S.H. Stevens, D. Spector, P. Riemer, Enhanced coalbed methane recovery using CO2 injection: worldwide resource and $\mathrm{CO} 2$ sequestration potential, in: SPE International Oil and Gas Conference and Exhibition in China, Society of Petroleum Engineers, 1998.

[12] S. Day, R. Fry, R. Sakurovs, Swelling of Australian coals in supercritical CO 2, International Journal of Coal Geology, 74 (2008) 41-52.

[13] M. Vandamme, L. Brochard, B. Lecampion, O. Coussy, Adsorption and strain: the CO 2-induced swelling of coal, Journal of the Mechanics and Physics of Solids, 58 (2010) 1489-1505.

[14] J. Liu, Z. Chen, D. Elsworth, H. Qu, D. Chen, Interactions of multiple processes during CBM extraction: a critical review, International Journal of Coal Geology, 87 (2011) 175-189.

[15] Y. Peng, J. Liu, M. Wei, Z. Pan, L.D. Connell, Why coal permeability changes under free swellings: New insights, International Journal of Coal Geology, 133 (2014) 35-46.

[16] J.W. Larsen, The effects of dissolved CO 2 on coal structure and properties, International Journal of Coal Geology, 57 (2004) 63-70.

[17] S. Mazumder, A.A. Karnik, K.-H.A. Wolf, Swelling of coal in response to $\mathrm{CO} 2$ sequestration for ECBM and its effect on fracture permeability, Spe Journal, 11 (2006) 390-398.

[18] Z. Pan, L.D. Connell, A theoretical model for gas adsorption-induced coal swelling, International Journal of Coal Geology, 69 (2007) 243-252. Letters, 22 (1995) 1397-1400.

[20] S. Mazumder, K.-H. Wolf, K. Elewaut, R. Ephraim, Application of X-ray computed tomography for analyzing cleat spacing and cleat aperture in coal samples, International Journal of Coal Geology, 68 (2006) 205-222.

[21] R. Ye, C. Xiang, J. Lin, Z. Peng, K. Huang, Z. Yan, N.P. Cook, E.L. Samuel, C.-C. Hwang, G. Ruan, Coal as an abundant source of graphene quantum dots, Nature communications, 4 (2013).

[22] B.G. Kutchko, A.L. Goodman, E. Rosenbaum, S. Natesakhawat, K. Wagner, Characterization of coal before and after supercritical $\mathrm{CO} 2$ exposure via feature relocation using field-emission scanning electron microscopy, Fuel, 107 (2013) 777-786.

[23] F. Huggins, D. Kosmack, G. Huffman, R. Lee, Coal mineralogies by SEM automatic image analysis, Scanning Electron Microsc.;(United States), 1980 (1980).

[24] H.L. Ramandi, P. Mostaghimi, R.T. Armstrong, M. Saadatfar, W.V. Pinczewski, Porosity and permeability characterization of coal: a micro-computed tomography study, International Journal of Coal Geology, 154 (2016) 57-68.

[25] V. Cnudde, B. Masschaele, M. Dierick, J. Vlassenbroeck, L. Van Hoorebeke, P. Jacobs, Recent progress in X-ray CT as a geosciences tool, Applied Geochemistry, 21 (2006) 826-832.

[26] D. Stauffer, Scaling theory of percolation clusters, Physics reports, 54 (1979) 1-74.

[27] M.J. Blunt, B. Bijeljic, H. Dong, O. Gharbi, S. Iglauer, P. Mostaghimi, A. Paluszny, C. Pentland, Pore-scale imaging and modelling, Advances in Water Resources, 51 (2013) 197-216.

[28] D. Wildenschild, A.P. Sheppard, X-ray imaging and analysis techniques for quantifying pore-scale structure and processes in subsurface porous medium systems, Advances in Water Resources, 51 (2013) 217-246.

[29] V. Cnudde, M.N. Boone, High-resolution X-ray computed tomography in geosciences: A review of the current technology and applications, Earth-Science Reviews, 123 (2013) 1-17.

[30] S. Iglauer, A. Paluszny, C.H. Pentland, M.J. Blunt, Residual CO2 imaged with X-ray microtomography, Geophysical Research Letters, 38 (2011).

[31] S. Iglauer, A. Paluszny, M. Blunt, Simultaneous oil recovery and residual gas storage: A porelevel analysis using in situ X-ray micro-tomography, Fuel, 103 (2013) 905-914.

[32] Y. Yu, W. Liang, Y. Hu, Q. Meng, Study of micro-pores development in lean coal with temperature, International Journal of Rock Mechanics and Mining Sciences, 51 (2012) 91-96. [33] L.M. Pant, H. Huang, M. Secanell, S. Larter, S.K. Mitra, Multi scale characterization of coal structure for mass transport, Fuel, 159 (2015) 315-323. 
[34] A. Buades, B. Coll, J.-M. Morel, A non-local algorithm for image denoising, in: Computer Vision and Pattern Recognition, 2005. CVPR 2005. IEEE Computer Society Conference on, IEEE, 2005, pp. 60-65.

325 [35] J.B. Roerdink, A. Meijster, The watershed transform: Definitions, algorithms and parallelization strategies, Fundamenta informaticae, 41 (2000) 187-228. obtained via X-ray microtomography: a review, Water Resources Research, 50 (2014) 3615-3639. [37] H.-H. Liu, J. Rutqvist, A new coal-permeability model: internal swelling stress and fracturematrix interaction, Transport in Porous Media, 82 (2010) 157-171. media: pore space partitioning based on morphological skeletonization, Journal of colloid and interface science, 221 (2000) 13-24. [39] J. Gale, P. Freund, Coal-Bed Methane Enhancement with CO2 Sequestration Worldwide Potential, Environmental Geosciences, 8 (2001) 210-217. [40] H. Sharma, S. Mazumder, T. Gilbert, M. Tovar, J.A. Philpot, Novel Approach to EUR estimation in Coal Seam Gas Wells, in: SPE Unconventional Resources Conference and Exhibition-Asia Pacific, Society of Petroleum Engineers, 2013. [41] M. Creech, B. McConachie, Reserve estimation and the influence of coal seams on coal seam gas productivity, in, Australasian Institute of Mining and Metallurgy, 2014. Procedia, 37 (2013) 6738-6745. 